\title{
An Empirical Study of Individual Behavior Constraints and Capital Allocation Efficiency in Financial Management
}

\author{
Qu Ziqiao \\ School of Management. Wuhan University of Technology, Wuhan, China \\ quziqiao16@163.com
}

Keywords: financial management, capital allocation

\begin{abstract}
The capital allocation of financial management service industry is effective as a whole, but it shows significant fluctuation. There are significant regional, provincial and industry differences in the efficiency of capital allocation of service industry, regions with low level of urbanization and economic development, provinces with strong industrial growth and value creativity, and lines with high monopoly or public service nature. Industry, capital allocation efficiency is low or invalid. Empirical analysis of the factors affecting the efficiency of capital allocation in service industry shows that the process of marketization and the financial development measured by bank deposits and loans, loan-to-deposit ratio and stock transaction amount can promote the efficiency of capital allocation in service industry, and the financial development measured by insurance density and insurance depth can promote the efficiency of capital allocation in service industry. The effect is not significant.
\end{abstract}

Financial management plays a decisive role in the individual restraint of resource allocation, in order to fully stimulate market vitality and improve the efficiency of resource allocation. The improvement of capital allocation efficiency means that under the fixed conditions of total social capital, monetary capital can flow efficiently among industries, regions and industries driven by long-term profit signals, so that capital resources can be allocated to industries and departments with good benefits, strong value creativity and high growth potential, so as to promote economic sustainability. Growth. Service industry is an important component of the national economy, an important symbol of modern economy and the main body of modern industry. It is necessary to accelerate the development of service industry, increase the proportion of service industry in the three industries, and make service industry grow into the leading industry of the national economy as soon as possible, so as to promote the adjustment of economic structure and accelerate the transformation of the mode of economic growth. It's the way. The key to effectively promote the sound and rapid development of the service industry is to actively guide the flow of social capital to the service industry, realize the continuous injection and accumulation of capital elements in the service industry, at the same time, transform the traditional service industry with the service industry capital, vigorously develop the emerging service industry, and focus on improving the efficiency of capital allocation in the service industry.

\section{Nonlinear regression analysis}

Nonlinear regression analysis is an important statistical method quickly growing up by dint of professional statistical software (such as SAS and SPSS, etc.) based on linear regression analysis in last one to two decades. Compared with the traditional linear regression analysis, it mainly targets the nonlinear (parameter) function relationship between random variables and variables to establish nonlinear regression model by using method of nonlinear least squares to fit, control and predict the physical problems. Thus, the nonlinear regression analysis is more complex either in processed object or processing method than linear regression. This chapter is mainly about the basic methods of nonlinear regression analysis, existing problems, estimate over initial value of related parameters and selection principle of model expectation function [5]. 
Set $\mathrm{Y}$ as an observable random variable, which is influenced by $\mathrm{m}$ non-random factor variables $x_{1}, X_{2}, x_{3} \ldots, x_{m}$ and random error $\mathrm{E}$, and has following non-linear relation with $x_{1}, x_{2}, X_{3} \ldots, x_{m}$

$$
y=F\left(x_{1}, x_{2}, \cdots, x_{m} ; \beta_{1}, \beta_{2}, \ldots, \beta_{p}\right)+E
$$

Where, F(.;.) represents nonlinear expectation function (i=l,2,..,m $\mathrm{j}=\mathrm{l}, 2, \ldots, \mathrm{P}) \quad$ of $\quad x_{i}$ and $\beta_{i}$; $\beta_{i}$ represents unknown parameter; E represents unobservable random disturbance variable and meets normal distribution and GauSS-Markov supposition

$$
\left\{\begin{array}{c}
E(\varepsilon)=0 \\
\operatorname{cov}\left(\varepsilon_{i}, \varepsilon_{i}\right)=\left\{\begin{array}{c}
\sigma^{2}(i=j) \\
0(i \neq j)
\end{array}\right.
\end{array}\right.
$$

Then equation (1) is called a nonlinear regression model. Observation data (called sample) of $\mathrm{N}$ times for random variable $\mathrm{Y}$ and non-random variable $\mathrm{X}$

$$
\left(x_{i 1}, x_{i 2}, \ldots, x_{i m} ; y_{i}\right) \quad i=1,2, \cdots, n
$$

meets following model:

$$
y_{i}=f\left(x_{i 1}, x_{i 2}, \cdots, x_{i m} ; \beta_{1}, \beta_{2}, \cdots, \beta_{p}\right)+\varepsilon_{i} \quad i=1,2, \cdots, n
$$

If let:

$$
Y=\left[\begin{array}{c}
y_{1} \\
y_{2} \\
\vdots \\
y_{n}
\end{array}\right] \quad F(X, \beta)=\left[\begin{array}{c}
F\left(x_{1}, \beta\right) \\
F\left(x_{2}, \beta\right) \\
\vdots \\
F\left(x_{n}, \beta\right)
\end{array}\right]=\left[\begin{array}{c}
F_{1} \\
F_{2} \\
\vdots \\
F_{n}
\end{array}\right] \quad \beta=\left[\begin{array}{c}
\beta_{1} \\
\beta_{2} \\
\vdots \\
\beta_{P}
\end{array}\right] \quad \quad \mathrm{E}=\left[\begin{array}{c}
\varepsilon_{1} \\
\varepsilon_{2} \\
\vdots \\
\varepsilon_{n}
\end{array}\right]
$$

Model (1) can be converted into a matrix

$$
Y=F(X, \beta)+E
$$

Nonlinear regression analysis is to fit and predict the data by establishing nonlinear regression model (6) for observation data of $\mathrm{n}$ times $\left(x_{i}, y_{i}\right)$. As data change characteristics and type of corresponding model expectation function are different, the construction modes of model can be divided into following three:

If $F(x, \beta)$ can be converted into a linear function via variable transformation and re-parameterization, and the random disturbance item $\mathrm{E}$ of transformed model still meets the condition of Gauss-Markov normal distribution, the processed object can be converted into a linear problem to be processed with linear regression method.

If $F(x, \beta)$ can be converted into a linear function via variable transformation, yet the random disturbance item $\mathrm{E}$ of transformed model no longer meets assumed conditions such as homogeneity of variance, the weighted linear regression method can be used.

If the expectation function $F(x, \beta)$ cannot be linearized or the random disturbance item $\mathrm{E}$ after linear transformation does not meet Gauss-Markov supposition and normal distribution condition, the nonlinear regression method is adopted, which is also the general method to process non-linear problem.

The main steps of nonlinear regression analysis include tallying and arrangement of observation data $\left(x_{i}, y_{i}\right)$, defining type of model expectation function, estimate over parameters iteration, and model parameters test, and finally the re-correction and practical application of model. 
(2) Analysis of Empirical Results

\section{Regional Analysis}

The results from the above analysis of the relationship between the national fiscal transfer expenditure and the per capita income ratio between urban and rural areas shows that although the national fiscal transfer expenditure has played a role in narrowing the income gap between urban and rural residents, it has not been very effective in alleviating the income gap between urban and rural areas. Then, we will divide the above 31 provinces, municipalities and autonomous regions into central, eastern and western regions to discuss the impact of fiscal transfer expenditure on these regions, to comprehensively compare the impact of transfer expenditure on regional income gap and urban-rural income gap. The regression results are shown in Table 1.

Table 1

\begin{tabular}{|c|c|c|c|c|c|c|c|c|c|}
\hline \multirow[t]{2}{*}{ Variable } & \multicolumn{3}{|l|}{ Central } & \multicolumn{3}{|c|}{ Eastern } & \multicolumn{3}{|c|}{ Western } \\
\hline & $\mathrm{Fe}$ & $\operatorname{Re}$ & Gmm & $\mathrm{Fe}$ & $\mathrm{Re}$ & Gmm & $\mathrm{Fe}$ & $\mathrm{Re}$ & Gmm \\
\hline \multirow{2}{*}{ lag term } & & & $0.9387 * * *$ & & & $0.8460 * * *$ & & & $0.95117^{* * *}$ \\
\hline & & & (26.59) & & & (29.06) & & & (32.32) \\
\hline \multirow[t]{2}{*}{ constant term } & $1.2826^{*}$ & $\begin{array}{l}1.5336 \\
* * *\end{array}$ & $0.2399 * *$ & $\begin{array}{l}1.6382 \\
* * *\end{array}$ & $\begin{array}{l}1.8669 \\
* * *\end{array}$ & $0.3976^{* * *}$ & $\begin{array}{l}4.9833 \\
* * *\end{array}$ & $\begin{array}{l}4.3922 * * \\
*\end{array}$ & 0.0450 \\
\hline & (1.84) & $(4.17)$ & (2.14) & (6.31) & (11.35) & (5.04) & (6.61) & $(11.70)$ & $(0.27)$ \\
\hline \multirow[t]{2}{*}{$\begin{array}{l}\text { transfer } \\
\text { expenditure }\end{array}$} & $0.0013^{* * *}$ & $\begin{array}{l}0.0013 \\
* * * \\
\end{array}$ & -0.0001 & $\begin{array}{l}0.0003 \\
* *\end{array}$ & 0.0002 & 0.0000 & $\begin{array}{l}-0.0016 \\
* *\end{array}$ & $\begin{array}{l}-0.0014 * \\
*\end{array}$ & -0.0003 \\
\hline & (3.04) & (3.17) & $(-0.40)$ & (2.02) & (1.50) & $(0.74)$ & $(-2.35)$ & $(-2.02)$ & $(-1.47)$ \\
\hline \multirow[t]{2}{*}{$\begin{array}{l}\text { economic } \\
\text { growth }\end{array}$} & $1.1685^{* * *}$ & $\begin{array}{l}1.1558 \\
* * *\end{array}$ & $-0.6175^{* * *}$ & $\begin{array}{l}1.5615 \\
* * *\end{array}$ & $\begin{array}{l}1.7529 \\
* * *\end{array}$ & -0.0093 & $\begin{array}{l}2.3682 \\
* * *\end{array}$ & $\begin{array}{l}2.3890 * * \\
*\end{array}$ & $-0.6780 * * *$ \\
\hline & (3.97) & 4.13 & $(-3.76)$ & (5.88) & (6.77) & $(-0.07)$ & (4.65) & (4.73) & $(-3.27)$ \\
\hline \multirow[t]{2}{*}{ population } & 0.0001 & 0.0001 & $0.0000^{* * *}$ & 0.0000 & 0.0000 & $0.0000^{* * *}$ & -0.0003 & -0.0000 & $0.0000^{* * *}$ \\
\hline & $(0.95)$ & $(1.43)$ & (2.92) & $(0.08)$ & $(0.55)$ & (5.99) & $(-1.16)$ & $(-0.41)$ & $(4.40)$ \\
\hline \multirow[t]{2}{*}{$\begin{array}{c}\text { fixed } \\
\text { capital }\end{array}$} & $-0.0001^{* * *}$ & $\begin{array}{l}-0.0001 \\
* * *\end{array}$ & $-0.0000^{* *}$ & $\begin{array}{l}-0.000 \\
0\end{array}$ & 0.0000 & $-0.0000 * * *$ & 0.0000 & 0.0000 & -0.0000 \\
\hline & $(-3.74)$ & $(-3.91)$ & $(-2.31)$ & $(-0.11)$ & $(0.43)$ & $(-5.47)$ & (1.52) & $(1.27)$ & $(-1.48)$ \\
\hline \multirow[t]{2}{*}{$\begin{array}{l}\text { industrial } \\
\text { structure }\end{array}$} & $1.3040^{* * *}$ & $\begin{array}{l}1.3189 \\
* * *\end{array}$ & 0.0782 & $\begin{array}{l}1.2214 \\
* * *\end{array}$ & $\begin{array}{l}0.6176 \\
*\end{array}$ & -0.0490 & $\begin{array}{l}-1.9757 \\
* *\end{array}$ & $\begin{array}{l}-2.2885 * \\
* *\end{array}$ & $0.5243^{* *}$ \\
\hline & (2.86) & $(3.08)$ & $(0.47)$ & $(3.00)$ & (1.73) & $(-0.62)$ & $(-2.27)$ & $(-2.84)$ & (2.55) \\
\hline $\begin{array}{l}\text { sample } \\
\text { capacity }\end{array}$ & 128 & 128 & 120 & 176 & 176 & 165 & 192 & 192 & 180 \\
\hline
\end{tabular}

$* * *, * *$ and $*$ represent the significance levels of $1 \%, 5 \%, 10 \%$, respectively.

Through the above analysis, we found that, at the national level, fiscal transfer expenditure has narrowed the income gap between urban and rural areas to different extent in different regions. In addition to the fact that fiscal transfer spending in the west has a certain effect on narrowing the income gap between urban and rural areas, the fiscal transfer expenditure has little effect on or even expand the income gap between urban and rural areas in the eastern region, and it has a light role in widening the income gap between urban and rural residents in the central region. This is different from the original intention of our policy.

\section{Conclusion}

To improve the efficiency of capital allocation in financial management: First, we should actively promote the process of marketization, give full play to the decisive role of the market in resource allocation, actively guide financial capital and social capital to infiltrate into the service industry, and form a diversified service industry capital input system. Secondly, to give full play to the role of banking industry in the development of service industry, China's banking industry should not only gradually change from an extension-oriented expansion with additional institutions and expanding financial business to an intensive growth with the purpose of regulating financial behavior, optimizing financial institutions, improving financial services and improving financial 
efficiency, but also create openness.

\section{References}

[1] WUR GLER J. Financial markets and the allocation of capital[J]. Journal of financial economics, 2000, 1(58): 187 -214.

[2] BAGEHOT W. Lombard Street: A Description of the Money Market[M]. Jondon: John Murray, 1873.

[3] R. I. MCKINNON. Money and Capital in economic development[M]. Washington D. C. : The Brookings Institution, 1973.

[4] SHAW E. Financial Deepening in Economic Development[M]. Oxford: Oxford University Press,1973.

[5] DIAMOND D. W. Financial Intermediation and Delegated Monitoring[J]. Review of Economic Studies, 1984, 51(3): 393 -414. 